\title{
NOVO MÉTODO DE PREPARAÇÃO PALINOLÓGICA PARA AUMENTAR A RECUPERAÇÃO DE DINOFLAGELADOS
}

\author{
MARCELO DEARAUJO CARVALHO \\ Museu Nacional, UFRJ, RJ, Brasil. \\ TAÍSSA RÊGOMENEZES \\ GEO, CENPES, PETROBRAS, RJ, Brasil. \\ CECÍLIA CUNHA LANA \\ BPA, CENPES, PETROBRAS, RJ, Brasil. \\ WOLFRAM WALTER BRENNER \\ Universität Kiel, Alemanha.
}

ANTONIO DONIZETI DE OLIVEIRA, JOÃO GRACIANO MENDONÇA FILHO

Lab. de Palinofácies e Fácies Orgânica, DEGEO, IGEO, UFRJ, RJ, Brasil.donnizzetti@yahoo.com.br

\begin{abstract}
RESUMO - O método aqui apresentado tem por objetivo melhorar a recuperação de palinomorfos em amostras de sedimentos quaternários da bacia de Campos. Nas preparações tradicionais, tanto palinológicas quanto de palinofácies, a fração mineral é eliminada por acidificação, com o objetivo de concentrar o maior número possível de palinomorfos e de matéria orgânica nas lâminas. Entretanto, ambas utilizam o descarte do sobrenadante após o ataque com ácidos. A principal diferença entre o novo método e as preparações tradicionais de palinologia e palinofácies é o peneiramento do material, ao invés do descarte do sobrenadante, com aproveitamento total do resíduo orgânico. Além disso, acrescentou-se a utilização de um procedimento simples e artesanal, o bateamento, para eliminar os minerais pesados do resíduo que sobram depois do ataque com ácido fluorídrico. Também são empregados, nesse novo método, detergente e ultra-som, para dissociar e eliminar a matéria orgânica amorfa. Além disso, não é necessário o uso de acetólise, diferentemente da preparação palinológica convencional para amostras do Quaternário. Uma vantagem adicional da nova metodologia é a utilização de menor quantidade de amostra (cerca de 6 gramas). Para a constatação de sua eficácia foram preparadas duas amostras de um mesmo nível, para estudos de palinofácies (sem peneiramento) e com a nova metodologia (com peneiramento). Os resultados mostraram-se bastante satisfatórios, revelando que a nova metodologia aumenta significativamente o número de dinocistos recuperados. $\mathrm{Na}$ amostra preparada para palinofácies foram contados 319 palinomorfos, contra 1017 palinomorfos obtidos na nova preparação. Quanto aos dinoflagelados, na lâmina de palinofácies foram contados apenas dois cistos, perfazendo $1 \%$ do total de palinomorfos da amostra. No novo método, os dinoflagelados atingiram $78 \%$ do total dos palinomorfos contados. Verificou-se que a nova preparação propiciou apenas o aumento da recuperação de dinoflagelados, sem a diminuição dos outros palinomorfos (pólens e esporos). Podemos concluir que o novo método possibilita uma maior recuperação de dinoflagelados em menor quantidade de amostra, além de uma menor quantidade de matéria orgânica amorfa na lâmina, o que facilita a identificação dos palinomorfos, especialmente dos dinoflagelados.
\end{abstract}

Palavras-chave: dinoflagelados, preparação palinológica, recuperação de palinomorfos.

ABSTRACT - NEW METHOD OF PALYNOLOGICAL PREPARATION FOR INCREASING THE RECOVERY OF DINOFLAGELLATES. This new methodology arises the needs to improve the recovery of marine palynomorphs Quaternary sediments of Campos basin. The objective of the palynological preparation is to eliminate the mineral constituents through acidifications, thus concentrating the palynomorphs on the palynological slides. In this new method, it is add the use of a simple and artisan procedure: of panning to eliminate the heavy minerals in the samples after the use of hydrofluoric acid. Additionally, the amorphous organic matter is dissociated with detergent and ultra-sound. The main difference between the method employed herein and the traditional one palynofacies is that the suspended material (after decantation) is sieved instead of the discard. For this method is not necessary the use of acetolysis, thus the dinoflagellates are better preserved. Another advantage of the method I is the use of lesser amount of sample (6 grams). To confirm the effectiveness 


\begin{abstract}
of the used method was compared one same sample prepared for method I and method II. The results show that the new method increases the number of dinoflagellates recovery. The sample prepared using the method II, were counted 319 palynomorphs, while in the sample prepared using the method II were counted 017 palynomorphs. This conspicuous difference between the methods is resulted of the high abundance of the recovery dinoflagellates. Using the method II, only two dinoflagellates were found. These two dinoflagellates are $1 \%$ of all palynomorphs of the sample. On the other hand, using the method I, the percentage of dinoflagellates reaches $78 \%$ of all palynomorphs of the sample. It seems that the increase of the dinoflagellates is not at the expense of other palynomorphs, because in both methods do not have difference in the results of palynomorphs count. According to these results, it is possible to confirm that the method greatly improves the recovery of dinoflagellates.
\end{abstract}

Key words: dinoflagellates, palynological preparation, recovery of palynomorphs.

\section{INTRODUÇÃO}

Este novo procedimento na preparação de lâminas palinológicas surgiu da necessidade de melhorar a recuperação de palinomorfos marinhos em amostras de sedimentos quaternários da bacia de Campos, preparadas pelo método padrão para estudos de palinologia e palinofácies, no Projeto "Aplicação da faciologia orgânica na modelagem paleoceanográfica e microbiofaciológica do talude continental brasileiro recente da bacia de Campos - RJ" (CTPetro/ CNPq/UFRJ - n ${ }^{\circ}$ 460492/00-4), o qual visa caracterizar, através de estudos taxonômicos e paleoecológicos dos dinoflagelados do furo Bu91-GL07, os parâmetros paleoambientais e paleogeográficos necessários à modelagem paleoceanográfica do talude continental. Para tanto, foram utilizados os testemunhos do furo Bu91-GL07, já anteriormente estudados pela PETROBRAS, que investe no detalhamento da seção quaternária do talude continental médio da bacia de Campos.

Os métodos aqui aplicados seguem os procedimentos descritos por Brenner (1998) para preparação palinológica e por Tyson (1995), Mendonça Filho (1999) e Carvalho (2001) para palinofácies. $\mathrm{O}$ estabelecimento de uma metodologia adequada de recuperação de palinomorfos, especialmente dos dinoflagelados, foi fundamental para o desenvolvimento da presente pesquisa. $\mathrm{O}$ método de preparação de sedimentos quaternários e recentes adotado nessa pesquisa é inédito no país. Essa preparação seguiu a metodologia proposta por Brenner (1996, 1998), que apresentam resultados bastante eficientes para a concentração de palinomorfos, notadamente de cistos de dinoflagelados. A amostragem do testemunho estudado e as etapas da preparação palinológica das amostras são descritas detalhadamente a seguir.

\section{METODOLOGIA}

\section{Amostragem}

O furo Bu91-GL07 é um testemunho contínuo e longo, com 100,20 m de comprimento, coletado a 955 m de lâmina d'água, no talude continental da bacia de Campos.

Os sedimentos lamosos compreendem cerca de $77 \%$ da seção testemunhada e foram classificados de acordo com suas cores - marrom ou oliva - que são função dos teores de carbonato de cálcio e sulfetos disseminados, e de origens pelágicas e hemipelágicas, respectivamente (Caddah et al., 1998). As areias foram classificadas de acordo com o conteúdo de lama, em areias limpas e areias lamosas (Caddah et al., 1998).

O material foi classificado de acordo com as seguintes litologias: lama oliva hemipelágica (Loh), areia lamosa (AL), lama oliva carbonosa (Loc), lama cinza esverdeada (Lce), lama cinza escuro esverdeada (Lc), lama preta esverdeada (Lpe), lama preta esverdeada com intercalações arenosas (Lpei) e lama cinza ( $\mathrm{Lcc})$.

Para material arenoso ou de coloração clara, o ideal na preparação palinológica é usar entre 50 g e 1 kg de sedimento, para uma boa recuperação de palinomorfos. Já para lamas e areias escuras, são suficientes, em média, de 5 a 8 g de material. Para o presente estudo, também foi levado em consideração a pouca quantidade de material disponível. Foi usado o peso de médio de 6,5 g de sedimento por amostra.

\section{Processamento palinológico das amostras}

Foram testadas duas metodologias para preparação palinológica de amostras, uma para análises de palinofácies e o método palinológico por peneiramento.

As lâminas preparadas para os estudos de palinofácies e fácies orgânica utilizaram os procedimentos palinológicos não oxidativos, segundo os padrões descritos por Tyson (1995) e Mendonça Filho (1999). Esta preparação foi realizada por Menezes (2002), para o estudo de palinofácies e fácies orgânica no poço Bu91-GL07. As etapas de isolamento do querogênio e preparação de lâminas organopalinológicas foram realizadas no Laboratório de Petrografia Orgânica do Centro de Excelência em Geoquímica (GEO/CENPES/ PETROBRAS), onde foi utilizado o Sistema de Neutralização de Resíduo Ácido desenvolvido por Assis (2000). Foram confeccionadas e observadas ao microscópio biológico 38 lâminas de palinofácies. As lâminas de palinofácies não apresentaram bons resultados para estudo de dinoflagelados, pois a recuperação dos cistos foi pequena (Figura 1: A, B).

Para o uso da metodologia mais adequada de processamento das amostras, fez-se um primeiro teste de preparação do material, em função da litologia recuperada pelo testemunho. Foi testada apenas $1 \mathrm{~g}$ de material arenoso e lamoso, representativos do poço Bu91-GL07, para verificação de como estas diferentes litologias reagiriam sob diferentes concentrações e tempos de exposição aos reagentes, ao uso ou não 


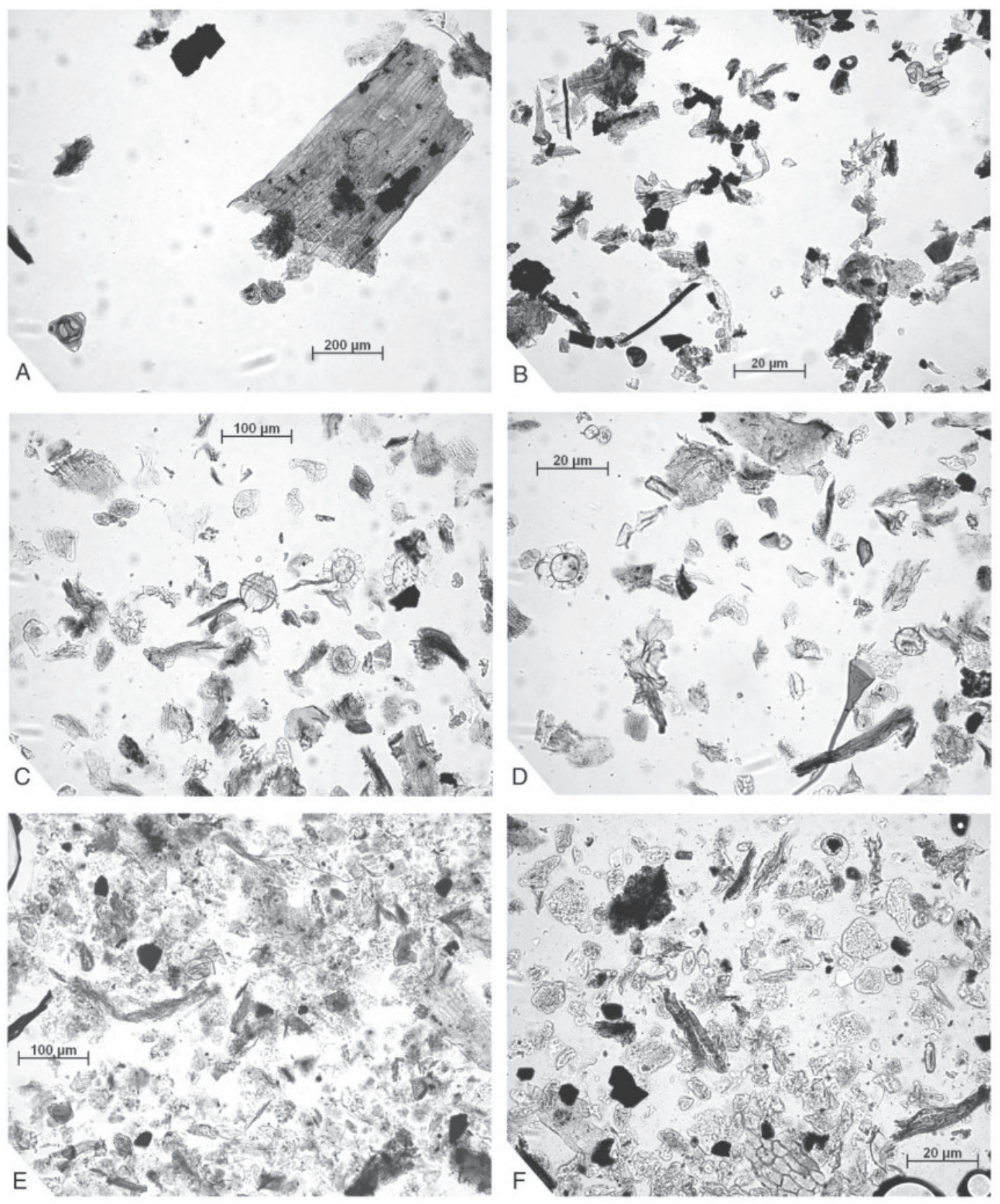

Figura 1. A, B: lâmina preparada pelo Método I (palinofácies), com recuperação de palinomorfos continentais e fitoclastos; C, D: lâmina preparada pelo Método II (palinológico proposto no presente trabalho), com bateamento, apresentando alta recuperação de dinoflagelados; E, F: preparação de lâmina pelo Método II, sem bateamento, apresentando abundantes minerais.

Figure 1. A, B: Method I (palynofacies), with recovering of continental palynomorphs and phytoclasts; C, D: Method II (palynologic method proposed in this paper), with panning process, presenting high recovered of dinoflagellates; E, F: Method II, without panning, presenting a high percentage of minerals.

de reagentes oxidantes e de detergentes para limpeza das amostras. Este tipo de teste economiza material para estudo, tanto de amostras quanto de reagentes químicos, e principalmente, tempo de preparação e análises. Com este teste, foi possível determinar o processamento a ser adotado para a preparação das 80 amostras coletadas. Neste mesmo teste foi constatado que seria necessária uma separação física de minerais pesados, que permaneceram nas amostras arenosas mesmo depois dos ataques com os ácidos, o qual foi chamada, aqui, de "bateamento".
Depois dos testes, optou-se pela adoção do "método palinológico por peneiramento" com o uso de $\mathrm{HCl}$ e $\mathrm{HF}$, associado ao detergente, ultra-som e seguido por bateamento.

\section{Material}

Foram utilizados os seguintes materiais para o processamento das amostras: sacos plásticos para armazenar as amostras, geladeira, balança de precisão, recipientes plásticos, peneiras cilíndricas com rede de poliéster com malha de $6 \mu \mathrm{m}$, papéis descartáveis, bastões de vidro, bastões de 
polipropileno, pipetas de vidro descartável, béqueres de vidro e polipropileno de $100 \mathrm{ml}, 250 \mathrm{ml}$ e $500 \mathrm{ml}$, garrafas plásticas, ácido clorídrico 32\% ( $\mathrm{HCl} 32 \%$ ), ácido fluorídrico $40 \%$ (HF 40\%), ultra-som, detergente comum, esponjas, bandejas de vidro, potes de filme fotográfico, lâminas de vidro Menzel SuperFrost Color (76 x 26 mm), lamínulas de vidro ( 24 × 24mm), corante safranina e gelatina glicerinada.

As peneiras são confeccionadas como segue: usa-se uma malha de poliéster com abertura de $6 \mu \mathrm{m}$, a qual é presa em potes plásticos aquecendo-se ambas com um pedaço de ferro quente. $\mathrm{O}$ diâmetro desses potes varia de acordo com a necessidade do trabalho, conforme a quantidade de material a ser peneirado. Para o presente trabalho foram utilizadas peneiras com $1 \mathrm{~cm}, 2 \mathrm{~cm}, 4 \mathrm{~cm}$ e $5 \mathrm{~cm}$ de diâmetro e altura igual ou maior aos respectivos diâmetros.

Wood et al. (1996), em seu estudo sobre processamento de amostras em laboratório recomendam atenção no manuseio dos ácidos que deve ser realizado em uma capela com o exaustor ligado. É necessário que o preparador utilize corretamente os equipamentos de segurança (avental, luvas de borracha, máscara com filtro para vapores ácidos, óculos de proteção, calçado apropriado etc.) para evitar acidentes.

\section{Identificação das amostras}

Inicialmente, as amostras foram analisadas em lupa para observação da cor, granulometria e forma dos grãos, litologia e possível ocorrência de carapaças de microfósseis. Após estes registros, cada amostra foi colocada sobre papel descartável, para evitar contaminações, e então pesada. É necessário colocar a identificação da amostra em todo o material utilizado no processamento (saco plástico, béqueres, peneiras, garrafas plásticas, vidros para armazenamento e lâminas).

\section{Metodologias de preparação palinológica}

A metodologia aqui descrita refere-se ao método de preparação de amostras para recuperação de microfósseis do tipo microplâncton de parede orgânica, como as cianobactérias (Cyanophyceae), clorofíceas (Chlorophyceae), prasinófitas (Prasinophyceae), acritarcos (Acritarchs) e dinoflagelados (Dinophyceae), sendo este último o principal objeto de estudo do presente trabalho.

Para o estudo de microfósseis orgânicos são geralmente adotados três métodos de preparação de amostras:

1. Palinofácies: recupera toda a matéria orgânica presente originalmente na amostra;

2. Paleopalinologia: utiliza compostos oxidantes, como hidróxido de potássio $(\mathrm{KOH})$ e ácido nítrico $\left(\mathrm{HNO}_{3}\right)$, para clareamento dos palinomorfos;

3. Palinologia por peneiramento: inclui etapas de acidificação ( $\mathrm{HCl}$ e HF), uso de detergente e ultra-som, sem descarte de material orgânico flotante.

Neste trabalho foi adotado o método utilizado por Brenner (1996, 1998, 2001), o "método palinológico por peneiramento" (Figura 1: C, D). O peneiramento favorece a remoção de material lenhoso, tecidos cuticulares, pequenos fitoclastos, concentrando os palinomorfos. Nas 80 amostras preparadas no Laboratório de Micropaleontologia da UFRJ, foram associados ao méto- do, por peneiramento, o uso de detergente, para dissociar e degradar a matéria orgânica amorfa, os pequenos fitoclastos e as cutículas. Foi usado ainda o ultra-som, por três segundos, para dissociar a matéria orgânica mais resistente, como fitoclastos, materiais cuticulares, membranas e matéria orgânica amorfa.

\section{Etapa de ataques ácidos}

Adotou-se o processamento de dez amostras por vez. A preparação de cada lote de amostras teve a duração de seis dias, da pesagem ao armazenamento do resíduo em vidro. Após a pesagem, coloca-se a amostra em um bequer de vidro de $250 \mathrm{ml}$. O ácido clorídrico ( $\mathrm{HCl}$ a $32 \%$ ) é acrescentado ao bequer até cobrir a amostra. Deixa-se a amostra em repouso na capela e espera-se o final da reação ou deixa-se o reagente agir por duas horas. $\mathrm{O} \mathrm{HCl} \mathrm{é} \mathrm{utilizado} \mathrm{para} \mathrm{eliminar} \mathrm{o} \mathrm{material}$ carbonático e alguns microorganismos como bactérias, nanofósseis, microforaminíferos e ostracodes. Caso este ataque inicial não seja suficiente para dissolver totalmente a fração carbonática, acrescenta-se mais ácido clorídrico $(\mathrm{HCl}$ a $32 \%$ ) e espera-se a reação cessar ou duas horas. Após o término da reação, ainda com o material dentro da capela, transfere-se o material do bequer para a peneira sem fazer descarte do líquido, isto é, todo o material atacado é colocado diretamente na peneira, utilizando-se para isto um pouco de álcool e água filtrada para limpar a parede do bequer.

A técnica de manejo da peneira inclui uma alternância de movimentos verticais e horizontais para que o material a ser estudado fique limpo, isto é, o material não desejável se desprenda do microplâncton de parede orgânica, principalmente dos cistos que possuem processos, espinhos ou outra ornamentação. Em geral, a matéria orgânica amorfa envolve esses microfósseis, o que dificulta a observação e principalmente a identificação dos microorganismos. O peneiramento oferece uma larga vantagem na remoção do material lenhoso, tecidos cuticulares, pequenos fitoclastos e matéria orgânica amorfa, isolando e concentrando os palinomorfos.

O material que passa pela peneira é depositado em um béquer vazio de $550 \mathrm{ml}$. Esse ácido clorídrico deve ser devidamente neutralizado e só então jogado fora. Depois do peneiramento, coloca-se a peneira com o material retido dentro de um béquer vazio de $550 \mathrm{ml}$, que será levado até uma pia para ser lavado com água corrente filtrada, para a neutralização da solução ácida. Esta lavagem para neutralização também é realizada através de sucessivos peneiramentos. É importante notar que não ocorre descarte em qualquer etapa após o uso do ácido ou em qualquer outra etapa seguinte. A lavagem é feita até que a água se neutralize, ficando com o pH por volta de sete. Na prática, isto corresponde a repetir a lavagem por dez vezes, até que a água da lavagem saia limpa da peneira. $\mathrm{Na}$ última lavagem, uma esponja de espuma é colocada debaixo da peneira para que o excesso de água seja sugado deixando o material da peneira mais seco e para que o material com diâmetro abaixo de $6 \mathrm{~mm}$ seja eficientemente eliminado. Assim, bactérias, nanofósseis calcários e esporos de fungos são eliminados mais eficientemente. Com o material ainda dentro da peneira, coloca-se um pouco de detergente (Extran), em quantidade suficiente para cobrir a amostra e espalhar-se por toda a 
peneira. O uso do detergente ajuda na dissociação e degradação da matéria orgânica amorfa, dos pequenos fitoclastos e das cutículas. É preciso que o detergente atue em toda a amostra para a mesma ser devidamente limpa. Deixa-se a amostra descansar por volta de 15 a 30 minutos em uma bandeja de vidro. Coloca-se um pequeno suporte em baixo da peneira de modo que ela permaneça inclinada.

Após a reação com o detergente a amostra é lavada com água filtrada por peneiramento, por várias vezes, até a água ficar limpa de toda a espuma feita pelo detergente. Depois dessa etapa, a peneira tem que ser limpa com água de torneira sob pressão forte, esponja e sabão, e então colocada no ultra-som por dois minutos, para que sua malha seja limpa, evitando a contaminação e entupimento na peneira.

A próxima etapa é 0 ataque da amostra com ácido fluorídrico ( $\mathrm{HF}$ a 40\%). Acrescenta-se uma quantidade de ácido fluorídrico cerca de três vezes maior que o volume da amostra, em um recipiente de polipropileno e deixa-se repousar por volta de doze horas ou o tempo suficiente para a sílica ser completamente dissolvida. Uma vez terminada a reação, peneira-se o material dentro da capela, pois o HF é bastante tóxico e corrosivo.

O material para análise orgânica é lavado e peneirado novamente várias vezes até que a água fique neutralizada, seguindo a mesma técnica de movimentações verticais e laterais utilizada na lavagem do ácido clorídrico. Novamente acrescenta-se detergente e deixa-se a amostra reagir entre cinco a quinze minutos. O material é novamente lavado e peneirado até a sua total neutralização. Ainda com o material dentro da peneira, e com um pouco de água corrente filtrada, observa-se o material ao microscópio óptico.

\section{Eliminação da matéria orgânica amorfa}

Logo nos primeiros testes das amostras, verificou-se que seria necessário o uso do ultra-som para dissociar a matéria orgânica amorfa mais resistente. Brenner $(1996,1998)$ recomenda o uso de alguns produtos oxidantes, como o hidróxido de potássio $(\mathrm{KOH})$ e o ácido nítrico $\left(\mathrm{HNO}_{3}\right)$, que eliminariam parte da matéria orgânica amorfa, além de clarear os palinomorfos. No material mais antigo, onde a matéria orgânica sofreu carbonização em altas profundidades, esses reagentes são usados para clarear as amostras e facilitar a identificação e classificação dos palinomorfos (Uesugui, 1979). Entretanto, no material do Quaternário, os dinocistos são muito claros e muito mais frágeis do que os dinocistos de sedimentos mais antigos, e por isso o uso de oxidantes deve ser evitado.

Nesta fase do processamento, caso ainda permaneça na amostra muita matéria orgânica amorfa, pode-se recorrer às técnicas descritas a seguir. Usar detergente puro (sem água) na amostra, por 30 minutos, agitando o material de vez em quando. Com a matéria orgânica devidamente limpa e peneirada, transferir o material para um bequer de vidro com um pouco de água destilada e acrescentar $\mathrm{KOH}$ a $10 \%$, até que a cor da água fique castanho claro. Em seguida, acrescenta-se a mesma quantidade de fosfato de sódio $\left(\mathrm{Na}_{3} \mathrm{PO}_{4}\right)$ ou outro fosfato, coloca-se na chapa aquecedora a uma temperatura de $+/-80^{\circ} \mathrm{C}$ por dez minutos. A seguir deve-se lavar e peneirar o material até neutralizá-lo (se for necessário, pode-se usar o ultra-som por dois segundos).
Após os ataques com ácidos próprios do processamento usual, utilizar ácido nítrico $\left(\mathrm{HNO}_{3}\right.$ a $\left.60^{\circ} \mathrm{C}\right)$ por três a cinco segundos. Em seguida, peneirar e depois usar o hidróxido de potássio $\left(\mathrm{KOH}\right.$ a $10 \%$ a uma temperatura de $+/-80^{\circ} \mathrm{C}$ ) por dez minutos. A matéria orgânica amorfa das amostras deste trabalho foi eliminada usando-se detergente e ultra-som, em períodos variando entre um e três segundos.

\section{Eliminação mecânica de minerais}

Como as amostras aqui estudadas são constituídas predominantemente por areias lamosas, verificou-se a presença de uma grande quantidade de minerais após os ataques ácidos, como micas, nas lâminas testadas. Esta fração mineral prejudica as análises organopalinológicas, palinológicas e paleopalinológicas. Matsuoka (2000) sugere, para eliminar o excesso de minerais pesados do resíduo, um método mecânico artesanal que foi adotado neste trabalho por seu ótimo resultado. Depois dos ataques com os ácidos, caso reste alguma fração mineral (micas, silicatos e fluoretos), esta fração é separada através de um "bateamento" (Figura 1: E, F). Coloca-se o resíduo, já neutralizado e com um pouco de água, num vidro de relógio de $15 \mathrm{~cm}$ de diâmetro e balança-se o vidro em movimentos circulares, como os que são feitos com uma bateia para concentrar o ouro de aluvião. É preciso ter cuidado para não derramar a água, pois os palinomorfos estão suspensos na lâmina d'água. Depois de alguns giros circulares no vidro, o resíduo orgânico leve (palinomorfos) flutua e vai juntando-se no centro, na coluna da água. A fração mineral, mais pesada, concentra-se também, mas afunda mais rapidamente e fica no fundo do vidro, na parte central. Cuidadosamente, antes que todo o material decante, verte-se a água com o material flutuante para um recipiente ou pipetase a água com o material orgânico para outra peneira de $6 \mathrm{~mm}$. Os minerais pesados ficam no fundo do vidro de relógio. Assim, separa-se o material orgânico da fração mineral, de uma forma física e não química. O procedimento é feito com amostras muito arenosas ou que contenham muito mineral micáceo, onde o ataque com HF pode não ser muito eficaz. Testa-se a qualidade da amostra, colocando-se um pouco do material em uma lâmina com um pouco de água destilada.

\section{Coloração dos dinocistos}

Em geral, os dinoflagelados autotróficos do Quaternário são de difícil identificação em microscópio com luz branca por apresentarem-se praticamente transparentes, enquanto que, em microscópio com luz fluorescente, estes aparecem com brilho fluorescente. Ocorre o contrário com os dinoflagelados heterotróficos, que são identificados sem problema sob luz branca, por apresentarem uma cor marrom ou castanha. Uma possibilidade para a identificação de dinoflagelados autotróficos em microscópio com luz branca é o uso de produtos químicos de tingimento, os corantes Safranin (Safranina, corante vermelho) ou Fucsin (Fucsina, corante marrom). Esse tingimento foi utilizado, a princípio, como teste em 20 amostras desse trabalho. Como os resultados foram satisfatórios adotou-se o tingimento para todos os resíduos orgânicos.

A solução para corar o resíduo é a de 0,01 g de Safranina 
(sem fenol) para cada $1.000 \mathrm{ml}$ de água destilada, sugerindose, ainda, mistura de $50 \mathrm{ml}$ de água destilada e $50 \mathrm{ml}$ de álcool. Do resíduo final, pipeta-se três gotas em uma peneira com malha de $6 \mathrm{~mm}$, que fica perfeitamente encaixada em um vidro com tampa plástica (conjunto peneira/vidro para coloração). Nesse vidro é colocada a Safranina. A solução deve invadir a peneira o suficiente para cobrir toda matéria orgânica. Tampa-se o vidro e agita-se o sistema vidro/peneira para homogeneizar a mistura e efetivar o tingimento da amostra. $\mathrm{O}$ ideal é deixar o material ser tingido de um dia para o outro. Depois, peneira-se o material com água corrente filtrada, deixando apenas a matéria orgânica com um pouco de água. No dia seguinte, faz-se um teste para verificar se o material está efetivamente corado. Caso contrário, deixa-se à solução agir por mais tempo ou aumenta-se a concentração de corante. Novamente, pipeta-se o material para um vidro usando água destilada e adiciona-se três gotas de fenol no vidro com o material, que ficará armazenado.

\section{Confecção das lâminas palinológicas}

Para a confecção das lâminas utilizamos pipetas de vidro descartáveis para retirar o resíduo palinológico do recipiente onde a amostra foi armazenada. A lâmina é aquecida em chapa quente na temperatura de $60^{\circ} \mathrm{C}$ e, sobre ela, coloca-se 3 $\mathrm{mm}^{3}$ de gelatina glicerinada. Aguarda-se o derretimento da gelatina, sobre a qual são colocadas duas gotas do resíduo. Com um palito, mistura-se o resíduo e a gelatina glicerinada até a sua homogeneização. A água dessa solução deve evaporar completamente, e isso é verificado colocando-se a lamínula próxima da solução. Enquanto a solução contiver água, a lamínula ficará embaçada pelo vapor d'água. Isso é ruim, pois poderá ocorrer formação de bolhas. Após a evaporação, retira-se a lâmina da chapa quente, colocando-a sobre uma bancada clara, se possível, para observar se apresenta boa quantidade de material. Nem pouco, nem em excesso. Em seguida, coloca-se a lamínula sobre a lâmina, de forma a não deixar bolhas no material. Para vedar a lâmina, torna-se a colocá-la na chapa quente, com um pedaço de parafina de cerca de $4 \mathrm{~mm}^{3}$, que deve ficar encostado entre a lâmina e a lamínula. Aguarda-se a parafina derreter e penetrar completamente entre a lâmina e a lamínula. Retira-se a lâmina da chapa quente e após a secagem da mesma, o excesso de parafina das bordas é retirado com estilete. Por fim, limpa-se a lâmina com algodão e álcool.

\section{Procedimento de contagem}

Foram analisadas quatro amostras (amostras 1, 7, 12 e 13) para se adotar a metodologia de contagem. As análises quantitativa e qualitativa de palinomorfos do Quaternário foram adotadas na contagem dos diferentes palinomorfos e gêneros de dinoflagelados.

Foi confeccionado um gráfico para cada amostra em função do gênero de dinoflagelados versus sua variação a cada 50 formas contadas, num total de 300 , para se conhecer a freqüência de variação dos gêneros de dinoflagelados. Os gêneros tiveram uma variação maior entre 180 e 250 cistos de dinoflagelados contados. Após 250 partículas ocorre uma estabilização da curva quanto ao aparecimento de novos gêneros. Optamos pela contagem de 300 palinomorfos (inclusive os cistos de dinoflagelados) e em seguida contamos mais 300 espécimes de cistos de dinoflagelados por lâmina.

A contagem dos 300 palinomorfos reflete a composição original do material orgânico palinomórfico na lâmina que é composto por grãos de pólen, esporos, microplâncton de água doce (Botryococcus, Pediastrum), esporos de fungos, microplâncton marinho de parede orgânica (Prasinophyta, acritarcas e dinoflagelados), ciliatas (tintinídeos), cianobactérias, microforaminíferos (paliniforaminíferos), ovos de vermes, ovos de copépodas, etc.. Paralelamente a essa contagem, também foram analisadas 38 lâminas organopalinológicas que nos forneceram o resultado da matéria orgânica total (Menezes, 2002). As espécies de dinoflagelados que ocorrem nas lâminas confeccionadas por peneiramento e a análise da matéria orgânica total (lâminas para estudos de palinofácies) possibilitaram dados mais precisos, principalmente, a respeito do paleoambiente.

\section{RESULTADOSECONCLUSÕES}

Os resultados mostraram-se bastante satisfatórios, revelando que este método aumenta significativamente o número de dinoflagelados recuperados. $\mathrm{Na}$ amostra preparada para palinofácies (Método I) foram contadas, primeiramente, 300 partículas da matéria orgânica total. Os resultados por componente, em percentual em relação à matéria orgânica total, podem ser observados abaixo.

Método I (palinofácies): matéria orgânica total.

Contagem: 300 partículas.

Resultado em percentual do total de matéria orgânica (100\%):

fitoclastos: $45 \%$

matéria orgânica amorfa: $25 \%$

esporos: $20 \%$

grãos de pólen: $2 \%$

microplâncton de água doce: $6 \%$

dinoflagelados: $1 \%$

componentes indeterminados: $1 \%$

Ainda na lâmina referente à amostra preparada para palinofácies (Método I), foi realizada uma segunda contagem, somente de palinomorfos, de lâmina inteira, obtendo-se como resultado:

Método I (palinofácies): somente palinomorfos.

Contagem: Contagem de lâmina inteira.

Resultado: $\mathrm{n}^{\circ}$ partículas contadas / percentual em relação aos palinomorfos (100\%):

esporos: 194 grãos / $62 \%$

grãos de pólen: 37 grãos / 12\%

microplâncton de água doce: 59 elementos / 20\%

dinoflagelados: 2 dinocistos $/<1 \%$

microforaminíferos (palinoforaminíferos): 0

outros: 18 elementos / $5 \%$

Total de elementos contados: 310 . 
O mesmo sistema de contagem utilizado anteriormente (somente palinomorfos em lâmina inteira) foi aplicado para a amostra preparada pelo novo método palinológico proposto (Método II), obtendo-se como resultado:

Método II (palinológico aqui proposto): somente palinomorfos.

Contagem: Contagem de lâmina inteira.

Resultado: $\mathrm{n}^{\circ}$ partículas contadas / em percentual em relação aos palinomorfos $(100 \%)$ :

esporos: 92 grãos / $9 \%$

grãos de pólen: 38 grãos / 4\%

microplâncton de água doce: 59 elementos / 6\%

dinoflagelados: 796 dinocistos / 79\%

microforaminíferos (palinoforaminíferos): 15 / 1,5\%

outros: 5 elementos / $0,5 \%$

Total de elementos contados: 1.005

Comparando-se os métodos utilizados constata-se que no sistema de contagem efetuado somente para palinomorfos, usando a contagem em lâmina inteira, foram contados 310 palinomorfos na amostra preparada para palinofácies (Método I - Figura 1: A, B), enquanto na amostra preparada pelo método aqui apresentado (Método II - Figura 1: C, D), foram contados 1.005 palinomorfos. Essa grande diferença entre um método e outro é devido ao grande número de dinoflagelados recuperados. No método de palinofácies foram contados apenas dois dinocistos que perfazem percentuais inferiores a $1 \%$ do total de palinomorfos dessa amostra. No método aqui apresentado o percentual dos dinoflagelados chega a $79 \%$ do total dos palinomorfos contados. Esse método propiciou um aumento (concentração) de dinoflagelados podendo, entretanto, ocorrer a diminuição de outros palinomorfos, notadamente de esporos.

O sistema de contagem utilizado para a matéria orgânica total só tem resultado no método de preparação para palinofácies (Método I), uma vez que a elevada concentração dos cistos de dinoflagelados, observada no Método II, se dá em detrimento de outros componentes orgânicos da matéria orgânica total.

Pode ser concluído que o método aqui apresentado possibilita uma maior recuperação de dinoflagelados em menor quantidade de amostra, além de uma amostra mais limpa devido ao peneiramento e ao uso do detergente que dissocia a matéria orgânica amorfa facilitando, assim, a melhor identificação dos palinomorfos, especialmente dos dinoflagelados.

A preparação palinológica por peneiramento, além de eliminar os constituintes mineralógicos por acidificação, mostra ótimos resultados quando se utiliza detergente e ultrasom para eliminar pequenos fitoclastos e dissociar a matéria orgânica amorfa. A utilização da peneira faz com que ocorra uma maior concentração dos palinomorfos. A não utilização de etapas de descarte é um dos principais responsáveis pela recuperação dos dinoflagelados do Quaternário, obtendo assim, o maior número possível de palinomorfos na lâmina palinológica.

\section{AGRADECIMENTOS}

Os autores agradecem ao CNPq/CTPETRO (projeto $\mathrm{n}^{\circ}$ 460-492/000-04) pelo apoio financeiro, e ao Laboratorio de Geologia/Unidade de Negócio de Exploração e Produção da Bacia de Campos/PETROBRAS pela liberação das amostras. Pelo apoio logístico e financeiro agradecem o Laboratório de Micropaleontologia/IGEO/CCMN/UFRJ, o Laboratório de Palinofácies e Fácies Orgânica/IGEO/CCMN/UFRJ e a Gerência de Bio-Estratigrafia e Paleoecologia (CENPES/ PETROBRAS). À Gerência de Geoquímica do CENPES/ PETROBRAS, pelo apoio analítico.

\section{REFERÊNCIAS}

Assis, JR. F. 2000. New Organic Matter Isolation Procedure and Equipment. In: LATIN AMERICAN CONGRESS ON ORGANIC GEOCHEMISTRY, 7, 2000. Anais, Foz do Iguaçu, ALAGO, p. 355-357.

Brenner, W.W. 1996. Mikro-Absorptionsphotometrie: neue Möglichkeiten der Faziesanalyse mit fossilen und rezenten Pollen. Neues Jahrbuch für Geologie und Paläontologie, Monatshefte, 1996(1):257-278.

Brenner, W.W. 1998. Grundlagen und anwendungsmöglichkeiten der mikro-absorptionsphtometrie für organisch-wandige mikrofossilien. Geomar Report, 76:38-106.

Brenner, W.W. \& Biebow, N. 2001. Missing autofluorescence of recent and fossil dinoflagellate cyst - an indicator of heterotrophy? Neues Jahrbuch füer Geologie und Paläontologie, Abhandlungen, 219(1/2):229-240.

Caddah, L.F.G; Kowsmann, R.O. \& Viana, A.R. 1998. Slope sedimentary facies associated with Pleistocene and Holocene sea-level changes, Campos Basin, southeast Brazilian Margin. Sedimentary Geology, 115(1/4):159-174.

Carvalho, M.A., 2001. Paleoenvironmental reconstruction based on palynological and palynofacies analyses of the AptianAlbian succession in the Sergipe Basin, northeastern, Brazil. Zur Erlangung der Doktorwürde der NaturwissenschaftlichMathematischen Gesamtfakultät der Ruprecht-Karls, Universität Heidelberg, Tese de Doutorado, 150 p.

Matsuoka, K. \& Fukuyo, Y. 2000. Technical Guide for Modern Dinoflagellate Cyst Study. WESTPAC-HAB/WESTPAC/IOC, $29 \mathrm{p}$.

Mendonça Filho, J.G. 1999. Aplicação de estudos de palinofácies e fácies orgânica em rochas do Paleozóico da Bacia do Paraná, Sul do Brasil. Programa de Pós-Graduação em Geociências, Universidade Federal do Rio Grande do Sul, Tese de Doutorado, 338 p.

Menezes, T.R. 2002. Aplicação de parâmetros palinofaciológicos e organogeoquímicos na reconstrução paleoambiental do talude continental brasileiro recente na Bacia de Campos - RJ. Programa de Pós-Graduação em Geociências, Universidade Federal do Rio de Janeiro, Dissertação de Mestrado, 174 p.

Tyson, R.V. 1995. Sedimentary Organic Matter. Organic facies and palynofacies. Londres, Chapman \& Hall, 615 p.

Uesugui, N. 1979. Palinologia: Técnicas de Tratamento de Amostras. Rio de Janeiro. Boletim Técnico da Petrobrás, 22(4):229-240.

Wood, G.D., Gabriel, A.M. \& Lawson, J.C. 1996. Palynological techniques-processing and microscopy. In: J. Jansonius \& D.C. McGregor (eds.) Palynology: principles and applications, American Association of Stratigraphic Palynologists Foundation, p. 29-50. 
